\title{
Índice fuzzy de qualidade de água para ambiente lótico - IQA $\mathrm{FAL}$ \\ IQA $A_{F A L}$ - FuzZy water quality index for lotic environments
}

\section{Marco Antonio Ribeiro Pessoa** (1), Flavio Joaquim de Souza², Patrícia Domingos $^{2}$ (D), José Paulo Soares de Azevedo ${ }^{1}$ (i)}

\section{RESUMO}

A divulgação de informações sobre qualidade das águas para um público não especialista é fundamental para subsidiar ações políticas e institucionais de gestão dos ambientes aquáticos. Para tanto, índices de qualidade de água têm sido propostos por serem capazes de sintetizar em um único valor ou categoria a informação, normalmente descrita a partir de um conjunto extenso de variáveis de qualidade de água. Este trabalho propõe um novo índice de qualidade de água, IQA $\mathrm{FAL}_{\text {', }}$ baseado em lógica nebulosa, direcionado para o ambiente lótico, desenvolvido com a colaboração do quadro de especialistas da área de qualidade de água do Instituto Estadual do Ambiente (INEA). O índice proposto foi aplicado a dados de qualidade de água do Rio Paraíba do Sul, obtidos pelo INEA, nos anos de 2002 a 2009. Os resultados do IQA $A_{\text {FAL }}$ mostraram que esse índice foi capaz de descrever a qualidade da água desse trecho do Rio Paraíba do Sul, correspondendo satisfatoriamente às avaliações de qualidade de água contidas nos relatórios disponíveis. Verificou-se também que com essa metodologia foi possível evitar que a influência de uma variável em condições críticas fosse atenuada pela influência das outras variáveis em condições favoráveis, produzindo um resultado impreciso no índice final.

Palavras-chave: índice de qualidade de água; lógica fuzzy; ambiente lótico; Rio Paraíba do Sul.

\begin{abstract}
The dissemination of information on water quality for a non-specialist audience is essential to support political and institutional actions for the management of aquatic environments. Therefore, water quality indices have been proposed since they are able to synthesize into a single value or category information, usually described from an extensive set of water quality variables. This research proposes a new water quality index, based on fuzzy logic, aimed at lotic environments, developed through the collaboration of experts in water quality of the Rio de Janeiro Environmental Agency (Instituto Estadual do Ambiente - INEA). The proposed index was applied to water quality data from the Paraíba do Sul River, obtained by INEA, in the years 2002 to 2009. The results of IQA $A_{F A L}$ showed that the index was able to synthesize the water quality of this stretch of the Paraíba do Sul, satisfactorily matching the assessments of the water quality assessments contained in the reports available. It was also noticed that with this methodology it was possible to avoid the attenuation of the influence of a variable in critical condition was attenuated by the influence of other variables in favorable conditions, producing an inaccurate result in the final index.
\end{abstract}

Keywords: water quality index; fuzzy logic; lotic system; Paraíba do Sul River.

\section{INTRODUÇÃO}

A água é um recurso natural imprescindível para a humanidade, entre outras razões, por ser um elemento cujo consumo diário é vital para a sobrevivência de todos os indivíduos. Além do consumo direto, a água é usada em quase todas as atividades desenvolvidas pelo homem. Seus usos múltiplos estão garantidos na legislação nacional, Lei n ${ }^{\circ}$ 9.433, de 08 de janeiro de 1997 (BRASIL, 1997), que institui a Política Nacional de Recursos Hídricos, entre os quais podemos destacar a irrigação, a produção de alimentos, os processos químicos industriais, a geração de energia, navegação, a harmonia paisagística e ainda o transporte de dejetos e resíduos em geral.

A gestão dos recursos hídricos tem se tornado, cada vez mais, uma questão preponderante para a humanidade devido à crescente escassez de reservas naturais de água (TUNDISI, 2001). Essa gestão tem, entre outras finalidades, por objetivo acompanhar as condições dos recursos hídricos, definir seus usos e propor melhorias (BRASIL, 1997).

Para uma eficiente gestão e o controle dos recursos hídricos, é indispensável um contínuo monitoramento da qualidade das águas,

口

'Universidade Federal do Rio de Janeiro - Rio de Janeiro (RJ), Brasil.

¿Universidade do Estado do Rio de Janeiro - Rio de Janeiro (RJ), Brasil.

*Autor correspondente: pessoamarco54@gmail.com

Recebido: 24/O3/2015 - Aceito: 29/10/2018 - Reg. ABES: 147587 
capaz de fornecer as informações necessárias ao adequado manejo desses ambientes aquáticos e das bacias contribuintes. O conhecimento e o acompanhamento das condições dos ecossistemas aquáticos vão traduzir-se em propostas de ações concretas buscando um equilíbrio entre o desenvolvimento socioeconômico e a preservação desse recurso.

Existe, entretanto, uma dificuldade intrínseca de comunicação entre aqueles que produzem o conhecimento sobre a qualidade das águas e aqueles que necessitam desse conhecimento para subsidiar ações gerenciais.

As informações obtidas com avaliação e interpretação dos dados de qualidade de água são, em geral, consolidadas em extensos e detalhados relatórios técnicos, baseados, geralmente, na análise individual de parâmetros físicos, químicos e biológicos

Buscar ferramentas que ajudem a traduzir as informações produzidas pelos especialistas em qualidade de água em uma linguagem acessível a um público não técnico tem sido objetivo de inúmeros trabalhos de pesquisa. Entre as propostas para reduzir esse lapso de comunicação, o desenvolvimento de índices de qualidade de água é bastante comum.

Índices de qualidade de água são tentativas de integrar, em um único valor, a informação descrita originalmente por um conjunto extenso de variáveis. O desafio está em como traduzir uma enorme massa de dados brutos em um valor ou uma categoria que expresse de forma simplificada e sintetizada a qualidade da água em determinado ambiente aquático.

\section{Índices de qualidade de água}

Horton (1965) foi o primeiro a desenvolver índices a partir da ponderação de variáveis de qualidade de água. Em 1970, a National Sanitation Foundation International (NSF, 2007) criou o Water Quality Index (WQI), com base em uma pesquisa que selecionou nove variáveis de qualidade de água com base na opinião de especialistas. Foram propostas, pelos especialistas, curvas para normalização das variáveis selecionadas em uma escala de 0 a 100, bem como pesos relativos, conforme a Equação 1.

$W Q I=\frac{\Sigma_{i} C i \times P i}{\sum_{i} P i}$

Em que:

WQI = a média ponderada dos parâmetros preestabelecidos, normalizados numa escala de 0 a 100 ;

$\mathrm{Ci}=$ o valor de cada parâmetro após a normalização;

$\mathrm{Pi}=\mathrm{o}$ valor do peso relativo de cada parâmetro.

As nove variáveis de qualidade de água utilizadas pelo WQI e seus respectivos pesos são: resíduo total $(0,8)$, temperatura $(0,10)$, turbidez $(0,8)$, demanda bioquímica de oxigênio (DBO) $(0,1)$, fósforo total $(0,1)$, oxigênio dissolvido $(\mathrm{OD})(0,17)$, potencial hidrogeniônico $(\mathrm{pH})(0,12)$, nitrogênio $(0,1)$ e coliformes termotolerantes $(0,15)$.
Em 1976, a Companhia de Tecnologia de Saneamento Ambiental de São Paulo (CETESB) modificou o WQI da NSF (2007), criando um índice a partir do produtório ponderado de nove variáveis analíticas de qualidade de água (CETESB, 2020), conforme a Equação 2. O índice desenvolvido pela CETESB tem como propósito a avaliação da qualidade de água para fins de abastecimento público, refletindo, principalmente, a contaminação do ambiente aquático pelo lançamento de esgotos domésticos.

$I Q A_{\text {CETESB }}=\Pi_{q=1}^{n} q_{i} w^{i}$

O índice da CETESB tem sido amplamente utilizado por diversas instituições governamentais de gestão e controle ambiental no Brasil.

A maioria dos índices de qualidade de água foi desenvolvida por especialistas em qualidade de água aplicando metodologias estatísticas, a partir da escolha de variáveis de qualidade de água e da ponderação de suas importâncias com a atribuição de pesos.

As metodologias tradicionais, entretanto, não têm se mostrado eficientes para representar o conhecimento de natureza mais subjetiva sobre as variáveis usadas para avaliar a qualidade dos ambientes aquáticos (LERMONTOV et al., 2008).

A lógica nebulosa é uma alternativa para modelagem de índices de qualidade de água, pois fornece outra abordagem para lidar com questões em que os objetivos não estão bem definidos e as informações não são precisas (CHAU, 2006).

Lermontov (2009) propôs um novo índice de qualidade de águas, o índice nebuloso de qualidade das águas (INQA), baseado em lógica nebulosa, e comparou os resultados obtidos com índices calculados por meio das diversas metodologias já propostas. No INQA foram

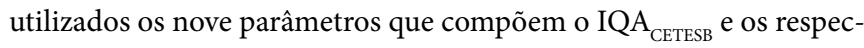
tivos conjuntos nebulosos foram criados com base nos intervalos, nas curvas e nas equações utilizados no IQA CETESB$_{\text {. }}$

Outros índices de qualidade de água baseados em lógica nebulosa foram desenvolvidos por Icaga (2007) e Ocampo-Duque et al. (2006).

Este trabalho propõe um novo índice, o índice fuzzy de qualidade de água para ambiente lótico $\left(\mathrm{IQA}_{\mathrm{FAL}}\right)$, desenvolvido com a contribuição de especialistas em qualidade de água do Instituto Estadual do Ambiente (INEA) Instituição de Planejamento e Controle Ambiental do Estado do Rio de Janeiro criada em 2007 com a fusão da Fundação Estadual de Engenharia do Meio Ambiente (FEEMA), do Instituto Estadual de Florestas (IEF) e da Superintendência de Rios e Lagoas

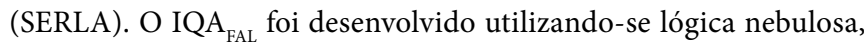
capaz de capturar com mais precisão o conhecimento dos especialistas e sua percepção subjetiva adquirida a partir da experiência profissional.

No desenvolvimento do IQA ${ }_{\mathrm{FAL}}$, buscou-se eliminar ou minimizar o efeito da atenuação da influência de valores muito ruins de determinado parâmetro, diante do comportamento equilibrado dos outros, 
conhecido como "efeito eclipse" (SILVA; JARDIM, 2006), muito comum nos índices tradicionais.

O índice desenvolvido foi calculado para uma série histórica de resultados de variáveis de qualidade de água obtidos em sete estações de amostragem no trecho do Rio Paraíba do Sul, entre o Reservatório de Funil e o município de Sapucaia. Os resultados são apresentados em mapas temáticos mostrando a variação espacial do índice na área de estudo e comparados com os resultados do índice de qualidade de água da CETESB aplicado aos mesmos dados.

\section{METODOLOGIA}

A lógica nebulosa (lógica fuzzy) surgiu, na década de 1960, com Lotfi Zadeh, que estendeu a teoria dos conjuntos e lógica booleana, que trata o mundo real como tendo apenas duas classes (verdadeiro ou falso), inserindo o conceito de verdade parcial.

Zadeh (1965) introduziu o conceito de pertinência, no qual um elemento pertence ao conjunto com um grau de pertinência associado.

O conceito de pertinência de um elemento a um conjunto, na teoria clássica dos conjuntos, é exclusivo, de forma que para um conjunto A em um universo $\mathrm{X}$, os elementos desse universo simplesmente pertencem ou não pertencem àquele conjunto, conforme a Equação 3.

$f_{A}(x)=\left\{\begin{array}{l}1 \text { se e somente se } x \in A \\ 0 \text { se e somente se } x \notin A\end{array}\right.$

Ao contrário da teoria dos conjuntos tradicional, o conceito de pertinência na lógica fuzzy permite que um elemento pertença parcialmente a mais de um conjunto ao mesmo tempo, e não obrigatoriamente a um único conjunto. Na lógica $f u z z y$ a função $f_{\mathrm{A}}$ pode assumir qualquer valor no intervalo [0,1], de modo que um conjunto $\mathrm{A}$ em um universo $\mathrm{X}$ é definido pela função de pertinência $\mu_{A}(x): X \rightarrow[0,1]$, representado por um conjunto de pares ordenados conforme a Equação 4.

$A=\left\{\mu_{A}(x) / x\right\} \quad x \in A$

Na qual:

$\mu_{A}(x)=$ o grau de pertinência de $x$ no conjunto A.

A lógica fuzzy trouxe o conceito de variável linguística, cujos valores são termos linguísticos, como expressões do tipo "alto", "baixo", "mediano", "muito alto" etc., o que permite processar "as informações subjetivas, de natureza vaga ou incerta, da linguagem natural" (ZADEH, 1973).

Uma das grandes vantagens desse modelo reside na possibilidade de capturar, com formalismo matemático, conceitos derivados dos termos linguísticos (OLIVEIRA JR., 1999).
Nessa metodologia, uma variável de qualidade de água como o OD, por exemplo, pode assumir, dependendo da faixa de variação, valores representados por termos linguísticos, como ANOXIA, para concentrações entre 0 e 2 mg. $L^{-1}$, e SUPERSSATURAÇÃO, para superiores a $10 \mathrm{mg} . \mathrm{L}^{-1}$. Os termos linguísticos e as fronteiras dos conjuntos nebulosos correspondentes são definidos pelo especialista em qualidade de água responsável pela modelagem.

Para cada termo linguístico que a variável linguística assumir será criado um conjunto nebuloso descrito por uma função de pertinência. A função de pertinência mapeia cada valor do conjunto nebuloso em um valor entre 0 e 1 , medida que representa o grau de pertinência do elemento no conjunto nebuloso (LERMONTOV, 2009).

As propriedades semânticas do conceito (termo linguístico) são descritas pelo contorno do respectivo conjunto nebuloso. Portanto, quanto mais próxima a curva da função de pertinência estiver do comportamento do fenômeno em estudo, melhor e mais preciso é o desempenho do modelo fuzzy na representação do mundo real (OLIVEIRA JR., 1999).

Por fim, os conjuntos nebulosos são associados por regras de inferência do tipo "se-então", em que, para as combinações entre conjuntos de entrada, são determinados conjuntos de saída.

A Figura 1 ilustra graficamente um exemplo de variável linguística, universo de discurso, termos linguísticos e função de pertinência.

\section{Desenvolvimento do IQA $\mathrm{FAL}_{\mathrm{L}}$}

O desenvolvimento do IQAFAL, índice de qualidade de água para ambiente lótico, usando a lógica fuzzy, foi realizado nas cinco etapas a seguir, não necessariamente de forma sequencial:

- Escolha das variáveis de qualidade de água (variáveis linguísticas);

- Definição dos universos de discursos e dos conjuntos nebulosos para cada variável de qualidade de água;

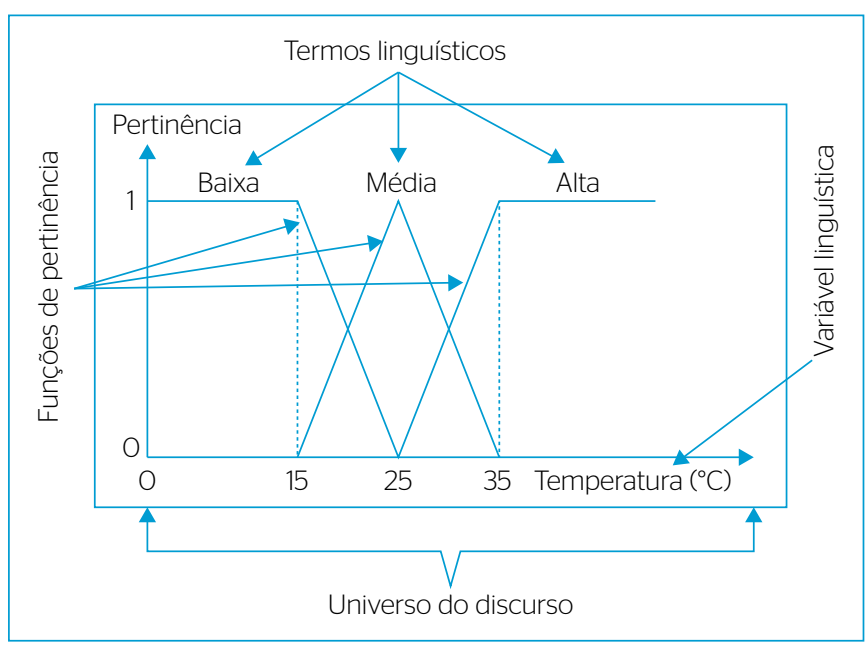

Figura 1 - Representação gráfica dos conceitos de variável linguística, universo de discurso, termos linguísticos e função de pertinência. 
- Definição das funções de pertinência para cada conjunto nebuloso;

- Determinação dos subíndices e das variáveis de qualidade de água que compõem os subíndices;

- Construção das bases de regras nas quais foram estabelecidas as regras, antecedente e consequente, para cada subíndice e para o índice final, o IQA ${ }_{\mathrm{FAL}}$.

Todas as etapas foram desenvolvidas a partir de um amplo debate com a equipe de especialistas em qualidade de água do INEA. Diversas versões do IQA $_{\mathrm{FAL}}$ foram implementadas com diferentes combinações de variáveis de qualidade de água, domínios, funções de pertinência, subíndices e base de regras em um processo interativo e iterativo até a versão final.

A versão final do $\mathrm{IQA}_{\mathrm{FAL}}$ utiliza sete variáveis de qualidade de água (Quadro 1) na sua formulação: duas variáveis biológicas que buscam descrever o equilíbrio do ecossistema aquático; duas variáveis químicas que representam o potencial de eutrofização do ambiente, assim como o grau de contaminação por esgotos; duas variáveis representativas da dinâmica de oxigênio (disponibilidade e consumo); e uma variável indicadora do grau de contaminação da água por fezes, que representa indiretamente o nível de risco de contaminação por doenças de veiculação hídrica.

Os organismos fitoplanctônicos foram escolhidos como descritores biológicos das condições da água no cálculo do $\mathrm{IQA}_{\mathrm{FAL}}$. Duas variáveis relativas ao fitoplâncton (número de taxa identificadas e número de indivíduos de cada táxon - indivíduo identificado e quantificado como uma unidade de classificação; na biologia pode ser um gênero, uma classe, uma família ou mesmo uma espécie) são aplicadas no cálculo do Índice de Diversidade de Shannon-Weaver (SHANNON, 1948), o qual é usado diretamente como a primeira variável biológica de qualidade de água na formulação do IQA $\mathrm{FAL}_{\text {. }}$.

A comunidade fitoplanctônica foi selecionada como variável-alvo, a partir de seus atributos qualitativos e quantitativos, em virtude das rápidas respostas que essa comunidade pode expressar às alterações ambientais (REYNOLDS, 1997; 2006; PADISÁK et al., 2006).

O número de células de cianobactérias, um grupo específico de organismos planctônicos, é a segunda variável biológica de qualidade

Quadro 1 - Variáveis de qualidade de água utilizadas no índice fuzzy de qualidade de água para ambiente lótico (IQA $\mathrm{FAL}_{\mathrm{L}}$ ).

\begin{tabular}{|l|c|}
\hline \multirow{2}{*}{ Tipo } & \multicolumn{1}{|c|}{ Nome } \\
\cline { 2 - 2 } & Índice de Diversidade de Shannon-Weaver \\
\hline \multirow{2}{*}{ Nutrientes } & Densidade de Cianobactérias \\
\cline { 2 - 2 } & Fósforo Total \\
\hline \multirow{2}{*}{ Oxigênio } & Oxigêênio Amonio Dissolvido \\
\hline Bacteriológica & Demanda Bioquímica de Oxigênio \\
\hline
\end{tabular}

de água utilizada na formulação do $\mathrm{IQA}_{\mathrm{FAL}}$. A densidade celular de cianobactérias reveste-se de um interesse especial, em função de sua importância nos ecossistemas aquáticos, relacionada aos eventos de florações tóxicas, particularmente em corpos d'água de abastecimento (CHORUS; BARTRAM, 1999). A ocorrência dessas florações representa um risco a mais para o ambiente, podendo afetar a biota local e a saúde pública. Além disso, trata-se de uma variável incorporada à Resolução CONAMA no 357/05 (BRASIL, 2005), legislação que define os padrões de classificação e enquadramento dos corpos d'água, e à Portaria $n^{\circ} 518$, do Ministério da Saúde (BRASIL, 2004), que define os padrões de potabilidade.

As variáveis fósforo total, nitrogênio amoniacal, OD e DBO foram escolhidas considerando que desempenham papel fundamental de descritores da integridade do ambiente aquático, sendo relacionadas aos impactos resultantes do lançamento de carga orgânica.

Os coliformes termotolerantes são um importante indicador de contaminação por fezes de animais de sangue quente. A presença desses organismos é um forte indício de lançamento de esgoto sanitário não tratado no corpo d'água.

Para cada uma das variáveis selecionadas para compor o IQA $\mathrm{FAL}_{\mathrm{L}}$ foram estabelecidos termos linguísticos, seus respectivos conjuntos nebulosos e suas funções de pertinência correspondentes. Os limites de cada conjunto nebuloso foram determinados a partir de uma ampla discussão entre os especialistas em qualidade de água do INEA, tendo como referência seu conhecimento e sua experiência profissional, sem perder de vista os valores indicados pela Resolução n 357/05 (BRASIL, 2005) como padrões para a classe II.

A variável $\mathrm{OD}$ foi particionada em cinco conjuntos nebulosos, para os quais foram atribuídos os termos linguísticos: ANOXIA, RUIM, REGULAR, BOM e SUPERSSATURAÇÃO (Figura 2).

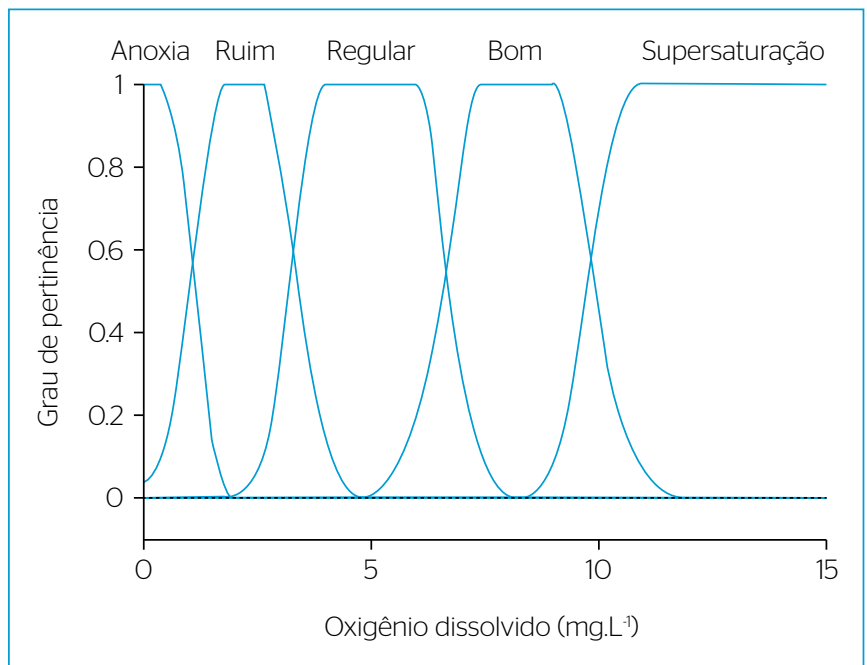

Figura 2 - Conjuntos nebulosos criados para a variável oxigênio dissolvido. 
A variável bacteriológica (coliformes termotolerantes) foi particionada em quatro conjuntos nebulosos, para os quais foram atribuídos os termos linguísticos: CRÍTICO, RUIM, REGULAR e BOM (Figura 3).

As outras variáveis que compõem o índice foram particionadas em cinco conjuntos nebulosos, para os quais foram atribuídos os termos linguísticos: EXCELENTE, BOM, REGULAR, RUIM e PÉSSIMO.

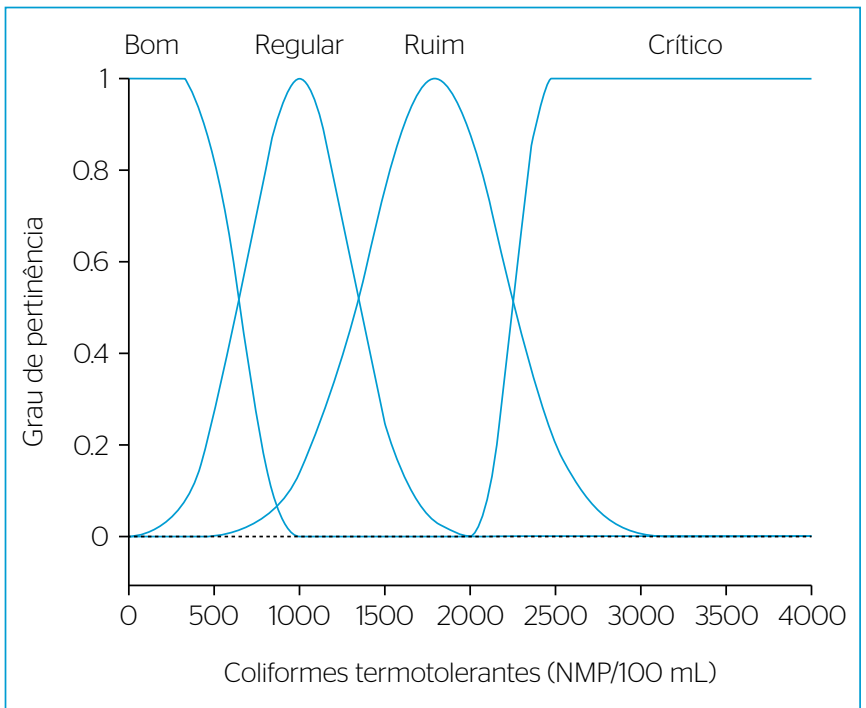

Figura 3 - Conjuntos nebulosos criados para a variável Coliforme Termotolerantes.

\section{Determinação dos subíndices}

A modelagem usando-se lógica fuzzy não costuma ser prática com mais de quatro variáveis de entrada por causa do crescimento exponencial das regras, o que torna difícil a criação e o gerenciamento destas. Para contornar essa limitação, costumam-se dividir as variáveis de entrada em sistemas fuzzy intermediários e usar a saída desses sistemas como entrada para o sistema final. Na modelagem do IQA $A_{\mathrm{FAL}}$, as sete variáveis de qualidade de água escolhidas foram organizadas em grupos que deram origem a subíndices que, por sua vez, foram usados como entrada para o índice final (Figura 4).

$\mathrm{O}$ universo de discurso do $\mathrm{IQA}_{\mathrm{FAL}}$, assim como dos subíndices, pode assumir valores entre 0 e 100 , em que 0 representa a pior qualidade, e 100, a melhor qualidade. Nesse intervalo foram estabelecidos cinco conjuntos nebulosos, para os quais foram atribuídos os termos linguísticos: PÉSSIMO, RUIM, REGULAR, BOM e EXCELENTE.

Os termos linguísticos utilizados no IQA $\mathrm{FAL}_{\mathrm{FL}}$ e nos seus subíndices são equivalentes às categorias utilizadas pelo Instituto Mineiro de Gestão das Águas (IGAM, 2005) para a classificação do seu índice (Quadro 2).

\section{Construção da base de regras}

Etapa em que foram estabelecidas as bases de regras para cada subíndice e para o índice final. O Quadro 3 mostra a base de regras criada para o índice IQA $\mathrm{FAL}$.

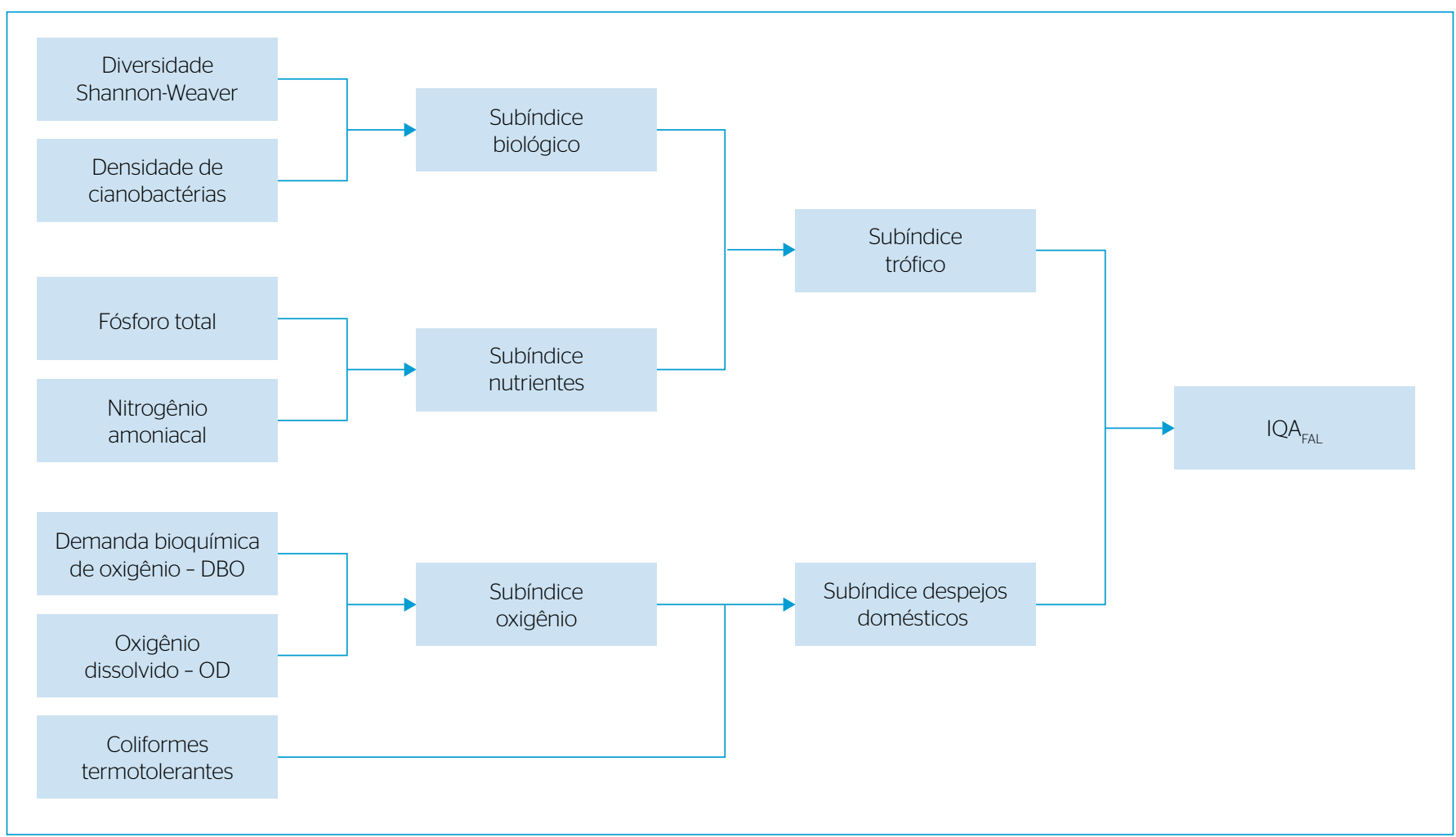

Figura 4 - Fluxograma dos Subíndices que formam o índice fuzzy de qualidade de água para ambiente lótico (IQA $\left.{ }_{\mathrm{FAL}}\right)$. 


\section{RESULTADOS}

O Rio Paraíba do Sul atravessa 37 municípios do Estado do Rio de Janeiro, em uma extensão de $500 \mathrm{~km}$. A importância desse curso d’água para a população fluminense pode ser descrita principalmente por ele ser essencial para o abastecimento de água de $85 \%$ da população da Região Metropolitana.

Quadro 2 - Categorias do índice de qualidade de água (IQA) desenvolvido pelo Instituto Mineiro de Gestão das Águas (IGAM).

\begin{tabular}{|l|c|}
\hline Nivel de Qualidade & Faixa \\
\hline Excelente & $90<$ IQA $\leq 100$ \\
\hline Bom & $70<$ IQA $\leq 90$ \\
\hline Médio & $50<$ IQA $\leq 70$ \\
\hline Ruim & $25<$ IQA $\leq 50$ \\
\hline Muito Ruim & $0 \leq$ IQA $\leq 25$ \\
\hline
\end{tabular}

Fonte: IGAM, 2005.

Quadro 3 - Base de regras para o índice fuzzy de qualidade de água para ambiente lótico $\left(\mathrm{IQA}_{\mathrm{FAL}}\right)$.

\begin{tabular}{|c|c|c|c|c|c|c|}
\hline & \multicolumn{5}{|c|}{ Subindice Despejos Domésticos } \\
\hline & & Excelente & Bom & Regular & Ruim & Péssimo \\
\hline \multirow{5}{*}{ 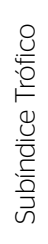 } & Excelente & Excelente & Bom & Regular & Ruim & Ruim \\
\hline & Bom & Excelente & Bom & Regular & Ruim & Ruim \\
\hline & Regular & Bom & Regular & Regular & Ruim & Péssimo \\
\hline & Ruim & Regular & Ruim & Ruim & Ruim & Péssimo \\
\hline & Péssimo & Regular & Ruim & Ruim & Péssimo & Péssimo \\
\hline
\end{tabular}

A Bacia do Rio Paraíba do Sul engloba uma área de aproximadamente $55.400 \mathrm{~km}^{2}$, distribuída nos Estados de Minas Gerais, de São Paulo e do Rio de Janeiro.

Em seu curso, que atravessa importantes polos industriais do eixo Rio-São Paulo, o Rio Paraíba do Sul sofre com a poluição resultante da falta de cuidados necessários com a qualidade ambiental, o que contribuiu, significativamente, para a degradação da qualidade de suas águas.

No Estado do Rio de Janeiro, a maior concentração industrial encontra-se localizada entre os municípios de Resende, Barra Mansa e Volta Redonda.

Problemas decorrentes da ausência de tratamento dos esgotos domésticos, na maioria das cidades, representam um importante fator de degradação da qualidade das águas dos rios da Bacia do Rio Paraíba do Sul.

A Figura 5 mostra a localização das sete estações de amostragem utilizadas neste trabalho.

$\mathrm{O} \mathrm{IQA}_{\mathrm{FAL}}$ foi calculado para todas as amostras obtidas pelo INEA entre 2002 e 2009. O número de amostras disponíveis para o cálculo do IQA ${ }_{\mathrm{FAL}}$, nessa série de dados, não é o mesmo em todas as estações de amostragem, variando entre 25 e 29 amostras.

$\mathrm{O} \mathrm{IQA}_{\mathrm{FAL}}$ é calculado para cada amostra individualmente. A metodologia adotada para avaliar os resultados foi utilizar uma visão agregada dos dados calculando-se, em cada estação de amostragem, os percentuais dos resultados do índice que ocorreram dentro de cada uma das categorias: PÉSSIMO, RUIM, REGULAR, BOM e EXCELENTE.

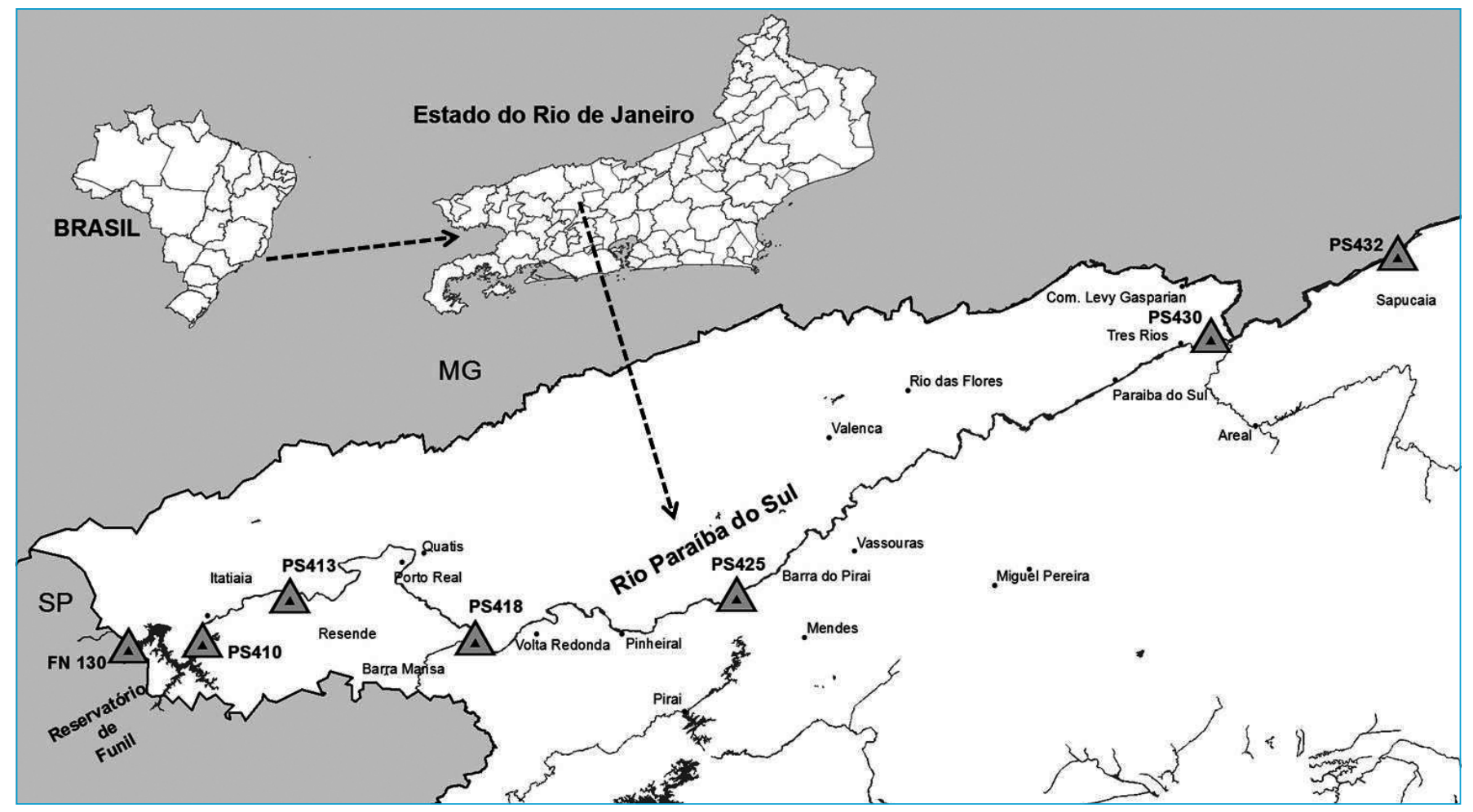

Figura 5 - Mapa com a localização das estações de amostragem utilizadas neste trabalho. 
A composição dos percentuais de resultados do IQA $\mathrm{FAL}_{\text {nas res- }}$ pectivas categorias, em cada estação, foi representada em gráficos de pizza. Esses gráficos são apresentados em um mapa temático, permitindo uma visão da variação espacial dos resultados do $\mathrm{IQA}_{\mathrm{FAL}}$ ao longo das estações de amostragem no Rio Paraíba do Sul.

Os maiores percentuais de resultados do $\mathrm{IQA}_{\mathrm{FAL}}$ em quase todas as estações de amostragem ocorrem na categoria RUIM. A estação de amostragem PS410, localizada na saída do Reservatório de Funil, é uma exceção, visto que o maior percentual dos resultados ocorre na categoria BOM (Figura 6).

Com o objetivo de comparar os resultados do $\mathrm{IQA}_{\mathrm{FAL}}$ foi realizado o mesmo procedimento utilizando-se o IQA ${ }_{\text {CETESB }}$ (CETESB, 2020).

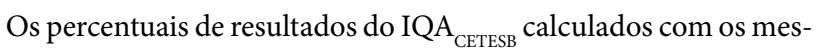
mos dados são apresentados em um mapa temático, com gráficos em pizza para cada estação de amostragem.

Os maiores percentuais de resultados do IQA ${ }_{\text {CETESB }}$, nas estações de amostragem ocorrem na faixa de valores da categoria REGULAR (Figura 7).

Comparando-se os resultados desses dois índices, percebe-se que o

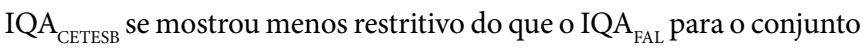
de dados utilizados, com exceção da estação de amostragem PS410.

Para detectar quais variáveis de qualidade de água empregadas neste estudo influenciaram mais fortemente os resultados do IQA $A_{\mathrm{FAL}}$, procedeu-se a uma avaliação em separado dos resultados de cada um dos subíndices que compõem o modelo final do $\mathrm{IQA}_{\mathrm{FAL}}$.

Verificou-se que, nas estações de amostragem localizadas no Rio Paraíba do Sul, os maiores percentuais de resultados do Subíndice Trófico ocorrem nas faixas de valores das categorias BOM e EXCELENTE.
Esses resultados indicam que as variáveis biológicas (índice de diversidade e cianobactérias) e os nutrientes (fósforo total e nitrogênio amoniacal) não estão determinando a resposta final do índice (Figura 4).

Por outro lado, os maiores percentuais de resultados do Subíndice Despejos Domésticos ocorrem nas categorias RUIM e PÉSSIMO, com exceção da estação de amostragem PS410, localizada na saída do Reservatório de Funil, na qual maior o percentual dos resultados ocorre na categoria BOM.

Isso indica que as variáveis ligadas ao metabolismo de oxigênio (OD e $\mathrm{DBO}$ ) e a variável bacteriológica (coliformes termotolerantes) são as que provavelmente estão determinando o comportamento dos

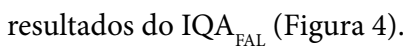

Os resultados do Subíndice de Oxigênio revelam que as variáveis $\mathrm{OD}$ e $\mathrm{DBO}$ não estão determinando os resultados do $\mathrm{IQA}_{\mathrm{FAL}}$, pois os maiores percentuais de resultados desse subíndice ocorreram nas categorias BOM e REGULAR.

O maior percentual de resultados de coliformes termotolerantes ocorre, em quase todas as estações de amostragem, na categoria CRÍTICO (concentrações maiores que $2.500 \mathrm{NMP} .100 \mathrm{~mL}^{-1}$ ). Na estação de amostragem PS410, os maiores percentuais de resultados de coliformes ocorrem na categoria BOM (concentrações de coliformes termotolerantes menores ou iguais a 300 NMP. $100 \mathrm{~mL}^{-1}$ ).

Pode-se verificar que, para o conjunto de dados utilizados neste trabalho, a variável de qualidade de água que tem maior influência nos resultados do IQA $\mathrm{FAL}_{\text {a }}$ são os coliformes termotolerantes, cujos resultados acompanham os do índice.

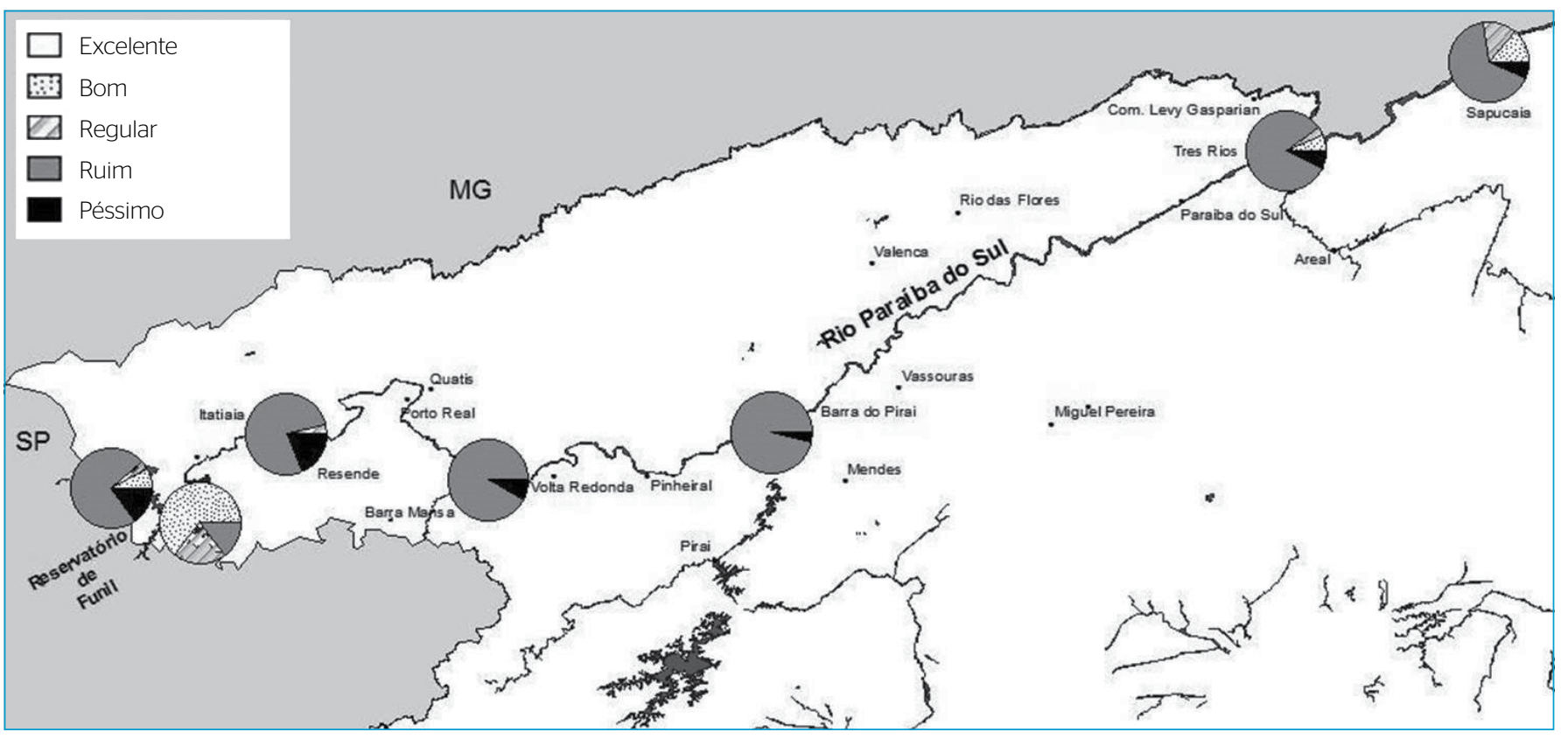

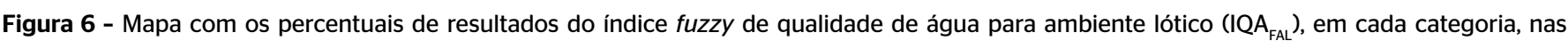
estações de amostragem. 


\section{CONCLUSÕES}

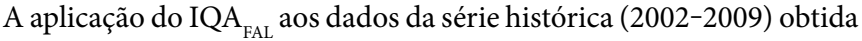
pelo INEA nas estações de amostragem ao longo de um trecho do Rio Paraíba do Sul revelam que os resultados desse índice coincidem com os relatórios (FEEMA, 2002; INEA, 2008a; 2008b).

A qualidade da água nesse trecho do Rio Paraíba do Sul é descrita em FEEMA (2002) como não apresentando condições críticas em termos de poluição orgânica, em consequência, principalmente, da capacidade de autodepuração desse curso d'água. Os resultados de OD e DBO, de modo geral, estão dentro dos padrões da Classe 2 do CONAMA (FEEMA, 2002). De maneira equivalente, no caso desse Subíndice Oxigênio, formado pelas variáveis OD e DBO, o maior percentual de seus resultados ocorre na categoria BOM. Esse trecho do rio sofre, entretanto, o impacto do lançamento de esgotos sanitários, o que se verifica por meio, principalmente, das elevadas concentrações de coliformes fecais (FEEMA, 2002).

A análise dos subíndices, separadamente, mostrou que, em quase todas as estações de amostragem, o parâmetro coliformes termotolerantes está determinando a maior ocorrência dos resultados do IQA $\mathrm{AAL}_{\mathrm{F}}$ na faixa de valores da categoria RUIM.

$\mathrm{O} \mathrm{IQA}_{\mathrm{FAL}}$ mostrou ser mais sensível na detecção de alterações da

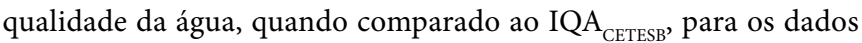
utilizados neste estudo. Observou-se, nos mapas temáticos, que, em quase todas as estações de amostragem, o maior percentual de resul-

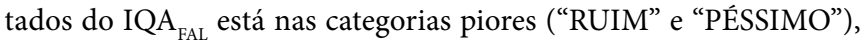
enquanto os resultados do IQA $\mathrm{CETESB}_{\text {estão predominantemente na }}$ categoria "REGULAR".

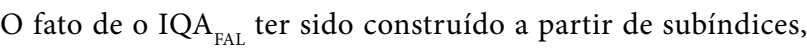
que incluem grupos de parâmetros de qualidade de água com significados semelhantes e complementares, ajudou a identificar qual variável de qualidade de água era mais determinante nos resultados do índice.

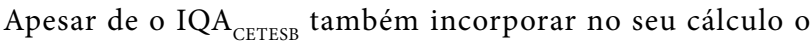
parâmetro coliformes termotolerantes com o segundo maior peso, os resultados desse índice na série analisada mostram sensibilidade menor aos altos valores desse parâmetro em quase todas as amostras.

Os resultados deste estudo sugerem que a metodologia utilizada na formulação do IQA $\mathrm{CETESB}_{\text {, }}$ apesar de incorporar a subjetividade do conhecimento do especialista por meio da atribuição de pesos diferenciados aos diversos parâmetros de entrada, não foi capaz de evitar o efeito da atenuação da influência de valores muito ruins de um determinado parâmetro, diante do comportamento equilibrado dos outros, fenômeno conhecido como efeito eclipse (SILVA; JARDIM, 2006).

No desenvolvimento do IQA ${ }_{\mathrm{FAL}}$ ficou clara a importância de uma metodologia que fosse capaz de incorporar a percepção do especialista de que alguns parâmetros de qualidade de água, dependendo da faixa em que se encontram, precisam determinar o resultado do índice de forma preponderante, independentemente dos valores dos outros parâmetros. Essa questão justifica-se pelo fato de que alguns parâmetros, a partir de certos valores, são determinantes para a avaliação da qualidade da água, ou seja, não é mais possível deixar que os valores dos outros parâmetros

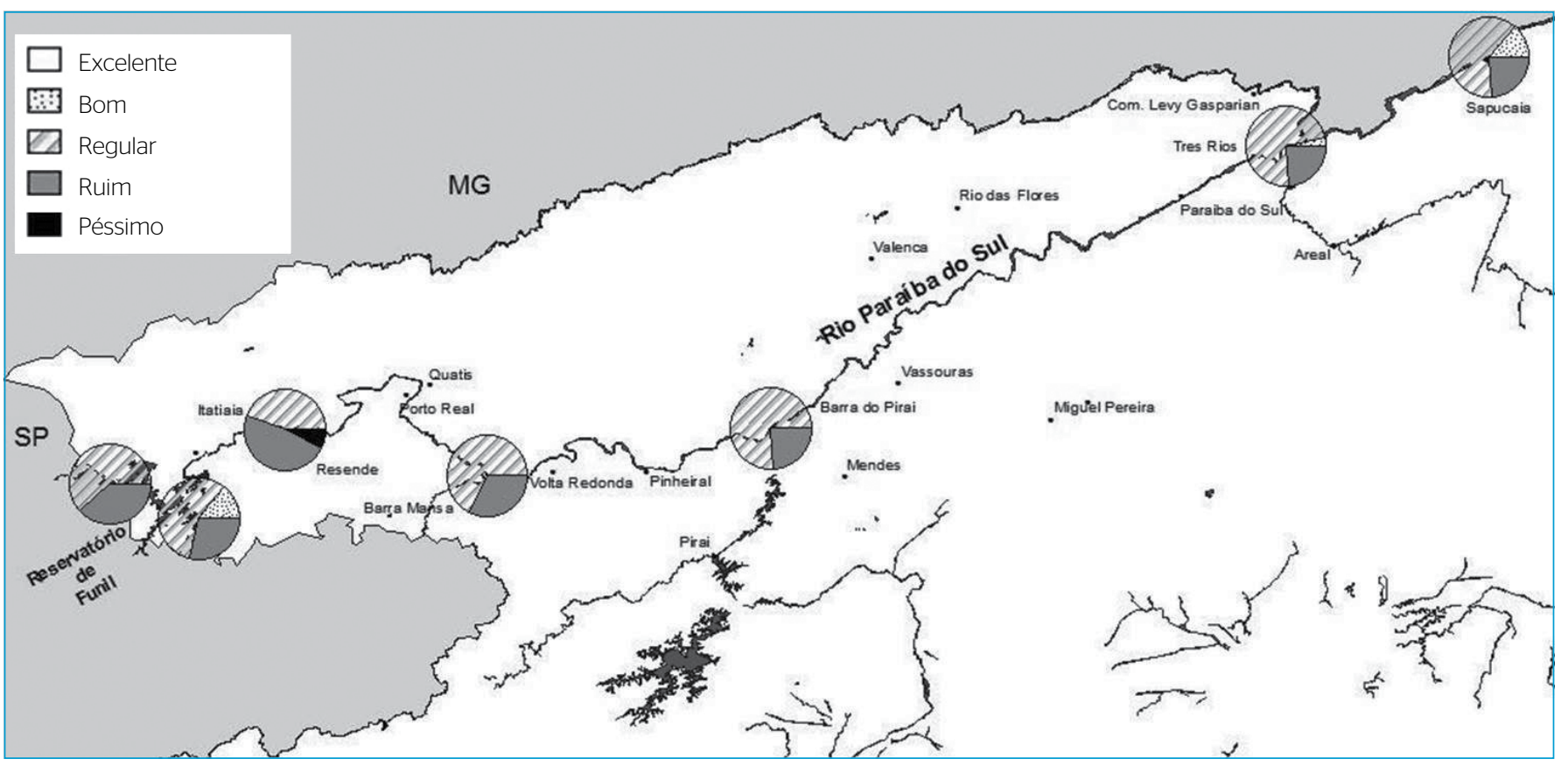

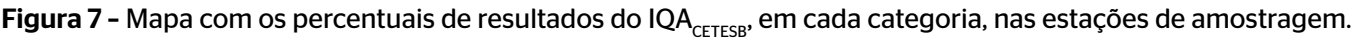


atenuem o resultado final. Nesse sentido, pode-se dizer que a metodologia utilizada na modelagem do $\mathrm{IQA}_{\mathrm{FAL}}$ se mostrou mais adequada para refletir a qualidade da água na série de dados utilizada neste trabalho.

A estação de amostragem PS410 é a única na qual a composição da série de resultados do $\mathrm{IQA}_{\mathrm{FAL}}$ no período é diferente das demais, pois o maior percentual de resultados ocorre na categoria BOM. Isso, segundo os especialistas, decorre do fato de essa estação se encontrar na saída do Reservatório de Funil, onde o tempo de residência das águas é bem maior do que no curso natural do rio, o que permite um decaimento das taxas de coliforme termotolerantes. Por isso, os valores desse parâmetro nessa estação estão em uma faixa inferior à das outras estações. Como coliforme termotolerantes mostrou ser o parâmetro que mais está influenciando os resultados do $\mathrm{IQA}_{\mathrm{FAL}}$, estes ocorrem em uma categoria melhor nessa estação.
Além disso, na estação de amostragem PS410 o maior percentual de resultados do Subíndice de Oxigênio ocorre na categoria REGULAR, enquanto nas outras estações ocorre na categoria BOM. Isso se deve ao fato de as concentrações de OD nessa estação serem inferiores às outras. Essas concentrações mais baixas de OD são explicadas pelo fato de essa estação estar localizada na saída do Reservatório de Funil, cujas águas são captadas a uma profundidade de aproximadamente $20 \mathrm{~m}$, onde as concentrações de OD são bem mais baixas do que as encontradas na superfície.

A metodologia aplicada no desenvolvimento do $\mathrm{IQA}_{\mathrm{FAL}}$ mostra ainda maior facilidade para lidar com diferentes variáveis de qualidade de água na modelagem do índice. A possibilidade de isolar grupos de algumas dessas variáveis em subíndices, com resultados independentes, descrevendo aspectos diferentes da qualidade da água, permitiu melhor análise e compreensão dos resultados obtidos e do raciocínio implícito do modelo.

\section{REFERÊNCIAS}

BRASIL. (1997) Política Nacional de Recursos Hídricos. Lei Federal no 9.433, de 8 de janeiro de 1997. Diário Oficial da União, Brasília.

(2004) Ministério da Saúde. Portaria no 518: estabelece os procedimentos e responsabilidades relativos ao controle e vigilância da qualidade da água para consumo humano e seu padrão de potabilidade. Diário Oficial da União, Brasília.

(2005) Conselho Nacional de Meio Ambiente. Resolução CONAMA nO 357: Padrões de lançamento e de qualidade do corpo receptor. Diário Oficial da União, Brasília.

CHAU, K.W. (2006) A review on integration of artificial intelligence into water quality modelling. Marine Pollution Bulletin, v. 52, n. 7 , p. 726-733. https://doi.org/10.1016/j.marpolbul.2006.04.003

CHORUS, I.; BARTRAM, J. (Eds.). (1999) Toxic Cyanobacteria in Water: A Guide to their Public Health Consequences, Monitoring and Management. Londres: E \& Fn Spon. 416 p.

COMPANHIA AMBIENTAL DO ESTADO DE SÃO PAULO (CETESB). (2004) Relatório de qualidade das águas interiores do Estado de São Paulo 2003. São Paulo: CETESB. Disponível em: <http://www.mp.sp. gov.br/portal/page/portal/cao_urbanismo_e_meio_ambiente/ biblioteca_virtual/bv_informativos_tecnicos/Relat\%C3\%B3rio\%20 Anual.pdf>. Acesso em: 17 jan. 2020

(2020) Qualidade das Águas Interiores no Estado de São Paulo | Apêndice D - Indices de Qualidade das Águas. São Paulo: CETESB. Disponível em: <https://cetesb.sp.gov.br/aguas-interiores/ wp-content/uploads/sites/12/2017/11/Ap\%C3\%AAndice-D\%C3\%8Dndices-de-Qualidade-das-\%C3\%81guas.pdf>. Acesso em: 17 jan. 2020
FUNDAÇÃO ESTADUAL DE ENGENHARIA DO MEIO AMBIENTE (FEEMA). (2002) Qualidade de Água do Rio Paraíba do Sul 1990/2001. Rio de Janeiro: Governo do Estado do Rio de Janeiro / Secretaria de Estado do Ambiente e Desenvolvimento Sustentável/Departamento de Planejamento Ambiental/Divisão de Qualidade de Água.

HORTON, R.K. (1965) An index number system for rating water quality. Journal of Water Pollution Control Federation, v. 37, n. 3, p. 300-306.

ICAGA, Y. (2007) Fuzzy evaluation of water quality classification. Ecological Indicators, v. 7, n. 3, p. 710-718. https://doi.org/10.1016/j. ecolind.2006.08.002

INSTITUTO ESTADUAL DO AMBIENTE (INEA). (2008a) Relatório de Avaliação da Qualidade de Água da Bacia do Rio Paraíba do Sul Ano 2008. Rio de Janeiro: Governo do Estado do Rio de Janeiro / Secretaria de Estado do Ambiente / Diretoria de Informação e Monitoramento Ambiental / Gerência de Avaliação de Qualidade das Águas.

(2008b) Relatório de Avaliação da Qualidade de Água da Sub-Bacia do Rio Guandu Ano 2008. Rio de Janeiro: Governo do Estado do Rio de Janeiro / Secretaria de Estado do Ambiente / Diretoria de Informação e Monitoramento Ambiental / Gerência de Avaliação de Qualidade das Águas.

INSTITUTO MINEIRO DE GESTÃO DAS ÁGUAS (IGAM). (2005) Estabelecimento das Equações do índice de Qualidade de Águas (IQA). Minas Gerais: Ministério do Meio Ambiente / Secretaria de Estado do Meio Ambiente e Desenvolvimento Sustentável de Minas Gerais / Unidade de Coordenação Estadual / Programa Nacional do Meio Ambiente / Subcomponente Monitoramento da Qualidade da Água. 
LERMONTOV, A. (2009) Novo Indice de Qualidade de Águas com uso da Lógica e Inferência Nebulosa. Tese (Doutorado em Ciências) - Tecnologia dos Processos Químicos e Bioquímicos, Universidade Federal do Rio de Janeiro.

LERMONTOV, A.; YOKOYAMA, L.; LERMONTOV, M.; MACHADO, M.A.S. (2008) Aplicação da Lógica Nebulosa na Parametrização de Um Novo Índice de Qualidade de Águas. Engevista, v. 10, n. 2, p. 106-125. https://doi.org/10.22409/engevista.v10i2.218

NATIONAL SANITATION FOUNDATION INTERNATIONAL (NSF) (2007) WQI - Water Quality Index. NSF. Disponível em: <http://www. nsf.org>. Acesso em: 17 jan. 2020.

OCAMPO-DUQUE, W.; FERRÉ-HUGUET, N.; DOMINGO, J.L; SCHUHMACHER, M. (2006) Assessing water quality in rivers with fuzzy inference systems: a case study. Environment International, v. 32, n. 6, p. 733-742. https://doi.org/10.1016/j.envint.2006.03.009

OLIVEIRA JR., H.A. (1999) Lógica Difusa: Aspectos Práticos e Aplicações. Rio de Janeiro: Interciência. 192 p.

PADISÁK, J.; BORICS, G.; GRIGORZKY, I.; CZKI-PINTÉR, E.S. (2006) Use of phytoplankton assemblages for monitoring ecological status of lakes within the Water Framework Directive: the assemblage index. Hydrobiologia. v. 553, p. 1-14.
REYNOLDS, C.S. (1997) Vegetation processes in the pelagic: a model for ecosystem theory. Germany: Ecology Institute. 371 p.

(2006) The ecology of phytoplankton. Nova York: Cambridge University Press. 535 p.

SHANNON, C.E. (1948) A mathematical theory of communication. Bell System Technical Journal, v. 27, n. 3, p. 379-423. https://doi. org/10.1002/j.1538-7305.1948.tb01338.x

SILVA, G.S.; JARDIM, W.F. (2006) Um novo índice de qualidade de águas para proteção da vida aquática aplicado ao rio Atibaia, região de Campinas/Paulínia - SP. Química Nova, v. 29 , n. 4 , p. 689-694. http://dx.doi.org/10.1590/SO10040422006000400012

TUNDISI, J.G. (2001) Água no século XXI: Enfrentando a escassez. São Carlos: Ed. Rima. 248 p.

ZADEH, L.A. (1965) Fuzzy Sets. Information and Control, v. 8, n. 3, p. 338-353. https://doi.org/10.1016/S0019-9958(65)90241-X

(1973) Outline of a New Approach to the Analysis of Complex Systems and Decision Processes. IEE Transactions on Systems, Man and Cybernetics, v. 3, n. 1, p. 28-44. https://doi.org/10.1109/ TSMC.1973.5408575 